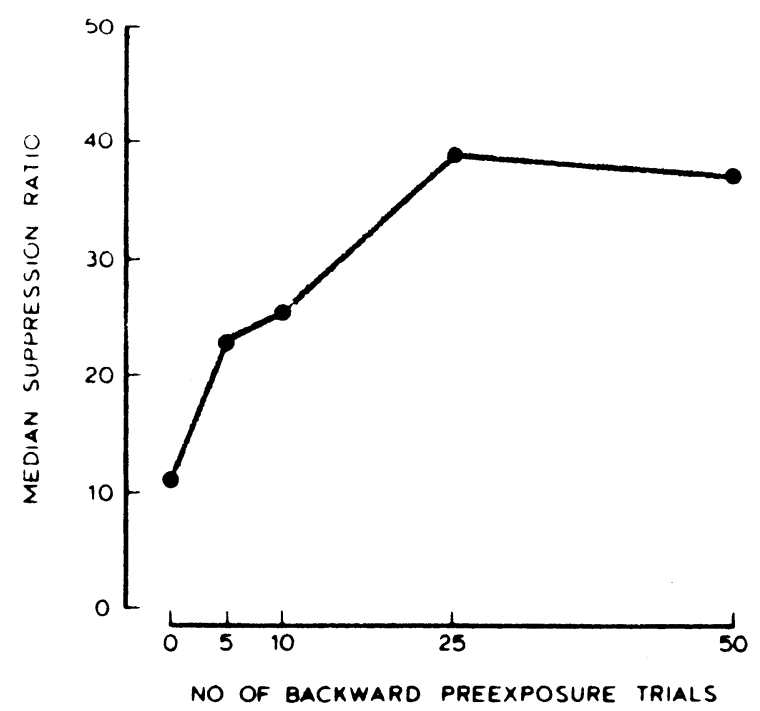

Fig. 1. Median acquisition suppression ratios for groups of rats given various numbers of backward-paired US and CS presentations prior to conditioned suppression acquisition.

experience with the conditioning stimuli in a backward-paired manner facilitates acquisition performance.

These results argue against Heth and Rescorla's (1973) suggestion that Siegel and Domjan (1971), although obtaining inhibitory effects with extensive backward training, would have obtained excitatory effects following fewer backward trials. The present results also suggest that the excitatory backward conditioning effects observed by Heth and Rescorla (1973) were probably produced by some factor other than the small number of backward conditioning trials presented.

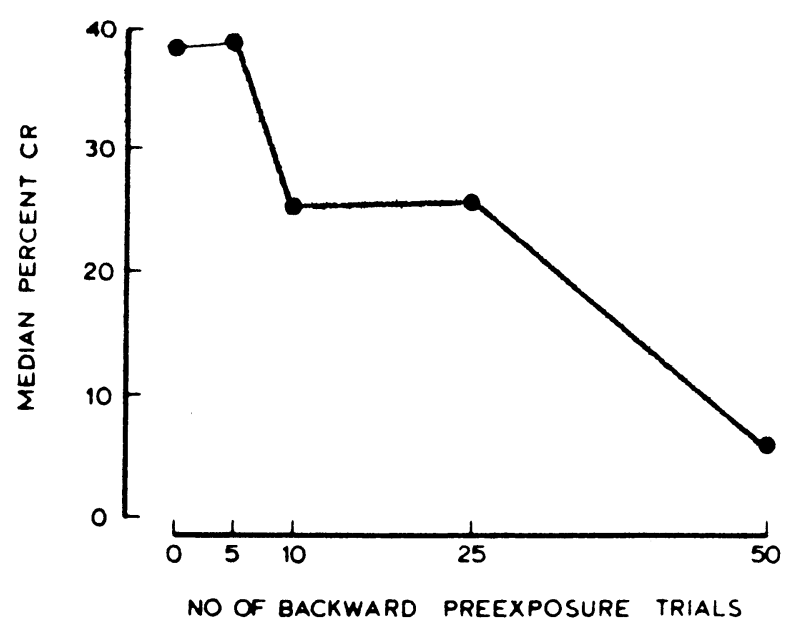

Fig. 2. Median acquisition percent CRs for groups of rabbits given various numbers of backward-paired US and CS presentations prior to eyelid conditioning acquisition.

\section{REFERENCES}

Gormezano, I. Classical conditioning. In J. B. Sidowski (Ed.), Experimental methods and instrumentation in psychology. New York: McGraw-Hill, 1966.

Heth, C. D., \& Rescorla, R. A. Simultaneous and backward fear conditioning in the rat. Journal of Comparative \& Physiological Psychology, 1973, 82, 434-443.

Moskovitch, A., \& LoLordo, V. M. Role of safety in the Pavlovian backward fear conditioning procedure. Journal of Comparative \& Physiological Psychology, 1968, 66, 673-678.

Siegel, S., \& Domjan, M. Backward conditioning as an inhibitory procedure. Learning \& Motivation, 1971, 2, 1-11.

(Received for publication June $7,1974$. )

Bulletin of the Psychonomic Society 1974, Vol. 4 (2B), 124-126

\title{
Replication: The persistent locomotion of immature rats*
}

\author{
PAUL M. BRONSTEIN $\dagger$ and TERRY DWORKIN \\ Brooklyn College of the City University of New York, Brooklyn, New York 11210
}

\begin{abstract}
In both cross-sectional and longitudinal experiments, 15-day-old domesticated rats were shown to locomote persistently in a maze. Thirty-day olds displayed a within-trial decrement in activity typical of adult patterns of ambulation. These data are consistent with the conclusion that 15-day olds may be behaviorally similar to adults with hippocampal lesions.
\end{abstract}

Recent evidence suggests that the 15-day-old rat is behaviorally similar to the adult following hippocampal lesions (Douglas, 1972). Compared to the animals aged 30 days or older, the 2-week-old rat shows (1) inferior acquisition of a passive-avoidance response (Riccio \& Schulenburg, 1969), (2) lower levels of spontaneous

*This work was supported by a grant from the Research Foundation of the City University of New York and is sponsored by $R$ alph $R$. Miller, who takes full editorial respondibility for its contents. We thank F. Dmitri Wolkoff for his technical assistance.

†Reprints: Paul M. Bronstein, Department of Psychology, Brooklyn College of the City University of New York, Brooklyn, New York 11210. alternation (Douglas, Peterson, \& Douglas, 1973), and (3) more persistent nose-poking behavior (Feigley, Parsons, Hamilton \& Spear, 1972). Bronstein, Neiman, Wolkoff, and Levine (1974), while skeptical about this central-nervous-system-based theory of behavioral development, did extend the known similarities between the juveniles and the lesioned adults. It was shown that the locomotion and rearing behaviors of the 15-day olds did not attenuate in open-field trials of 30 min duration. Animals as little as 6 days older, however, did demonstrate the activity decrements typical of adult rats.

The current investigation is an attempt, first to 


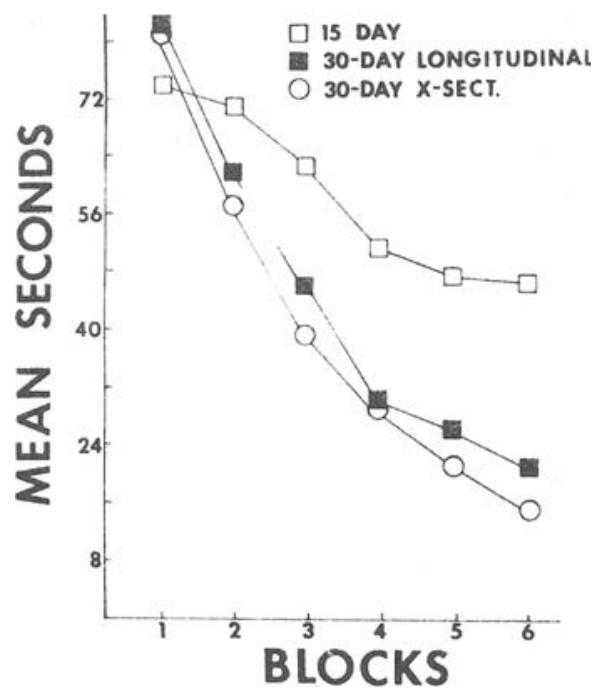

Fig. 1. Mean seconds ambulating as a function of age and intratrial blocks.

replicate the age-related findings of Bronstein et al (1974). The present design also replaces the open field with vertically and horizontally striped alleyways. This variant was chosen since vertical black-and-white stripes have been reported to differentially arouse activity in adult Ss (cf. Dember, 1965). Thus, age-related differences in the stimulus control of activity or exploration were also investigated. Finally, the present work examines this age-related change in activity with both longitudinal and cross-sectional investigations.

\section{METHOD}

\section{Subjects}

Forty-eight albino rats of Sprague-Dawley descent (6 litters of 8 pups), bred and raised in the Brooklyn College vivarium, were used. Animals were maintained on ad lib Purina Lab Chow and water in separate plastic litter cages along with their lactating dams. Each litter was culled to 5 males and 5 females on the day of birth (Day 0), although only 4 Ss of each sex were used to represent each litter. The colony was brightly illuminated $18 \mathrm{~h} /$ day ( 8 a.m. to 2 a.m.) with rats tested during the light part of the cycle. Both the colony and testing area were heated to about $74^{\circ} \mathrm{F}$.

\section{Apparatus}

Two identical square-shaped Plexiglas alleyways were used; each had an interior width of $6.4 \mathrm{~cm}, 7-\mathrm{cm}$ high walls, and sides $55.5 \mathrm{~cm}$ long (as measured along the outer wall). Both alleys were covered with clear Plexiglas, while the floors were white and of the same material. The walls of one maze were lined horizontally with black-and-white stripes, while the stripes of the second chamber were vertically oriented. All black stripes were $1.75-\mathrm{cm}$-wide veneer strips which had been painted flat black and glued to the white Plexiglas walls. The intervening space was $1.75 \mathrm{~cm}$ wide, and every wall was half white and half black. A $60-\mathrm{W}$ incandescent light was centered $76 \mathrm{~cm}$ above the tops of the two enclosures which were placed side by side. This bulb provided the only illumination and the positions of the two alleys were counterbalanced within each group.

\section{Procedure}

Each litter was separated into the 4 Ss that were tested both at Day 15 and at Day 30, and the 4 that were run only when 30 days old. The former are referred to as "longitudinal" Ss, while the others are termed "cross-sectional" animals. Furthermore, each of these groups was split (while counterbalancing for litter identity) into those 12 Ss given exposure to the horizontally lined chamber, with the others tested in the vertically lined apparatus. All pups had their eyes open by Day 15, and approximately half of each group was male.

Those rats run at both ages received two 30-min exposures to the same alley. The Ss tested only when 30 days old were removed from the litter for $1 / 2 \mathrm{~h}$ at Day 15 and placed into separate stainless steel cages (Wahmann, Model LC75/SA). Thus, all animals run at Day 30 had the same timing and amount of maternal separation. Pup identities were established by pelage marking following the Day-15 experience.

Testing consisted of carrying each $\mathrm{S}$ from the colony to the experimental chamber in a small bucket and placing the rat into one corner of the apparatus (facing into that corner) by temporarily displacing the top of the maze. E then operated two pushbuttons to record the duration of ambulation (defined as any quadrupedal walking or running) as well as the number of maze arms entered. A rat's whole body (except tail) had to be in an arm in order for the latter event to have been tallied. These two measures were accumulated automatically for every 5-min block of the 30-min trial.

Upon placement into a corner, an animal was judged to be occupying space in both of the intersecting arms. Hence, a rat entering the labyringh in, say, the sou th corner was required to turn one of the adjacent (east or west) corners in order for a first arm entry to have been recorded. The latency for this initial response was taken as well. Finally, both walls and floor were wiped clean with dilute acetic acid (2\%-3\%) following a pup's removal.

\section{RESULTS}

On each dependent variable, three kinds of comparisons were made. Three-way analyses of variance were used along with Newman-Keuls and two-tailed $t$ tests in making post hoc comparisons. Unless otherwise specified, $\mathrm{p}$ was set at .01 .

All analyses included the apparatus variable (horizontal vs vertical stripes) and the repeated measure of 5-min blocks. Finally, there was the variable of group identity: First, the 15-day olds were compared to themselves on a second trial (i.e., the 30-day-old longitudinal Ss). Second, the 2-week olds were compared to the 30-day-old cross-sectional Ss. Finally, the two groups of 30-day olds were compared. Age represented a within-S variable in the first of these analyses.

As noted in Figs. 1 and 2, the data concerning ambulation time and maze-arm entries were quite compatible. All six analyses of variance indicated a highly reliable within-trial decrement $(p<.01$ in all cases), but this effect was due mostly to the behavior of the two 30-day-old groups. In both cross-sectional and longitudinal analyses of each behavior, a significant Age by Blocks interaction was manifest. These second-order effects were due to the relatively pursistent activities of the younger Ss. Post hoc tests showed a significant 
within-trial decrement in ambulation time among the 15-day olds by Block 4. There was no reliable block-to-block waning of arm entries among the younger Ss. In fact, there was an increase in this activity between Blocks 1 and 2 (Newman-Keuls, $\mathrm{p}<.05$ ).

On both longitudinal and cross-sectional analyses of ambulation time, the 15-day olds were significantly more active than the 30-day olds on Blocks 4, 5, and 6 (correlated and independent t tests; $p<.01$ for all). On the arm-entries variable, the younger rats were reliably more active than the 30-day olds on Block 6 (cross-sectional ANOVA, $\mathrm{t}=2.77$, $\mathrm{df}=45, \mathrm{p}<.01$ ). There were no differences between age groups on the longitudinal analysis of arm entries from Blocks 2-6 $(\mathrm{t} \leqslant 1.41)$. On the first block, however, the 15 -day olds were found to enter reliably fewer maze arms than either of the older groups $(t \geqslant 6.32, p<.001, d f=21$ or 45 in the longitudinal and cross-sectional analyses, respectively). ${ }^{1}$

The orientation of the stripes in the two otherwise identical mazes had no discernible effect on the behavior of any group, and there was only one interaction involving the apparatus variable. In analyzing the arm entries of 2-week olds and 30-day old cross-sectional Ss, a reliable Age by Apparatus by Blocks interaction was observed $(\mathrm{F}=2.41, \mathrm{df}=5 / 220, \mathrm{p}<.05)$. This third-order effect resulted from the 15-day olds entering fewer arms in the vertically striped maze during Block 3 than the 15-day-old horizontal group. Essentially, the stimulus differences between mazes failed almost totally to affect the behavior of any group.

The cross-sectional and longitudinal 30-day olds did not differ from one another on either index of activity. Also, there were no Groups by Blocks interactions indicating that testing experience at Day 15 had.no detectible effect upon later behavior. This trend was apparent in the latency to first arm entry as well. The 15-day olds required a mean of $127.44 \mathrm{sec}$ to emit this response, while the means for each of the older groups fell between 17 and $19 \mathrm{sec}$. There was no overlap between the distribution of the times of the younger Ss and the range of latencies taken by either 30-day old group. The difference between the cross-sectional and longitudinal 30-day olds did not approach significance $(\mathrm{t}$ $=0.59, \mathrm{df}=44$, n.s.).

\section{DISCUSSION}

The present data support fully the previous work of Bronstein et al (1974), indicating that 15-day-old rats show a persistence of activity quite unlike conspecifics just a few days older. Hippocampectomized adults are similar to the 2-week- olds in this regard (cf. Roberts, Dember, \& Brodwick, 1962). Furthermore, the current study indicates that this rapid ontogenetic change can be demonstrated either longitudinally or in a cross-sectional design.

The visual patterns to which the animals were exposed failed to elicit any detectable behavioral changes; the two mazes were associated with near-identical behavior patterns in both age

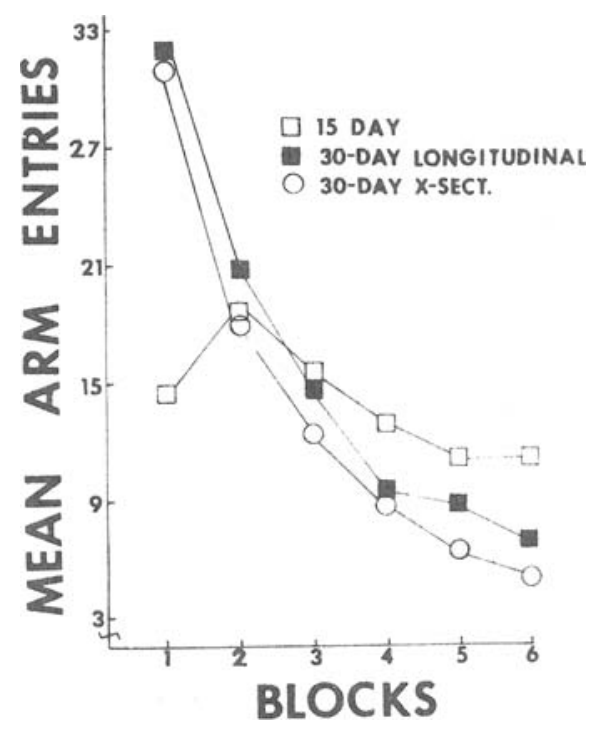

Fig. 2. Mean arm entries as a function of age and intratrial blocks.

groups. Similarly, it is unclear whether the present age-related changes are a manifestation of (1) the utilization of different cues in the two age groups, (2) the rapid development of a capacity for habituation, or (3) the ontogenesis of a potential for peripheral fatigue. Some ongoing work is designed to eliminate the uncertainties of interpretation associated with these consistent changes in locomotor activity.

Finally, it was noted that the two 30-day-old groups showed the same pattern of ambulation. That is, there were no aftereffects of a prior apparatus exposure among 15-day olds following a 15-day intertrial interval. Although comparisons with other age groups are not possible, this lack of retention among 15-day olds is not surprising in light of the memory deficits typical of immature rats (cf. Campbell \& Spear, 1972).

\section{REFERENCES}

Bronstein, P. M., Neiman, H., Wolkoff, F. D., \& Levine, M. J. The development of habituation in the rat. Animal Learning \& Behavior, 1974, in press.

Campbell, B. A., \& Spear, N. E. Ontogeny of memory. Psychological Review, 1972, 79, 215-236.

Dember, W. N. The new look in motivation. American Scientist, $1965,53,409-427$

Douglas, R. J. Pavlovian conditioning and the brain. In R. A. Boakes and M. S. Halliday (Eds.), Inhibition and learning. New York: Academic Press, 1972. Pp. 529-553.

Douglas, R. J., Peterson, J. J., \& Douglas, D. P. The ontogeny of a hippocampus-dependent response in two rodent species. Behavioral Biology, 1973, 8, 27-38.

Feigley, D. A., Parsons, P. A., Hamilton, L. W., \& Spear, N. E. Development of habituation to novel environments in the rat. Journal of Comparative \& Phy siological Psychology, 1972, 79, 443-452.

Riccio, D. C., \& Schulenburg, C. J. Age-related deficits in acquisition of a passive avoidance response. Canadian Journal of Psychology, 1969, 23, 429-437.

Roberts, W. W., Dember, W. N., \& Brodwick, M. Alternation and exploration in rats with hippocampal lesions. Journal of Comparative \& Physiological Psychology, 1962, 55, 695-700.

\section{NOTE}

1. Transient apparatus failures resulted in the loss of two Ss' data. Group means were substituted for the missing scores and the degrees of freedom reduced accordingly.

(Received for publication April 11, 1974.) 